\title{
A giant tumor of the mediastinum mixed with thymocytes and adipocytes: a case report
}

\author{
Hui Wang ${ }^{1 \#}$, Qiao Li ${ }^{2 \#}$, Qichang Jiang ${ }^{1}$, Yanmiao Yang ${ }^{1}$, Yang Liu ${ }^{1}$, Longfeng $\mathrm{Gu}^{1}$, Ming Gong ${ }^{2}$, Gang Xu ${ }^{1}$, \\ Cheng Chen ${ }^{2}$
}

${ }^{1}$ Department of Thoracic and Cardiovascular Surgery, The Second Affiliated Hospital of Zunyi Medical University, Zunyi, China; ${ }^{2}$ Department of Thoracic Surgery, The Affiliated Hospital of Zunyi Medical University, Zunyi, China

\#These authors contributed equally to this work.

Correspondence to: Gang Xu. Department of Thoracic and Cardiovascular Surgery, The Second Affiliated Hospital of Zunyi Medical University, Zunyi 563000, China. Email: xglhl333@163.com; Cheng Chen. Department of Thoracic Surgery, The Affiliated Hospital of Zunyi Medical University, 149

Dalian Road, Zunyi 563000, China. Email: 29217036@qq.com.

\begin{abstract}
A 17-year-old male was hospitalized for 6 months with chest tightness and shortness of breath. Chest CT showed large mixed density shadow of anterior mediastinum, multiple flaky fat density shadow, left lower lung compression, atelectasis, partial compression of right lung and obvious heart pressure. The patient's symptoms are caused by the compression of the heart and lung by the mediastinal mass. The results of routine examination were normal. After excluding surgical contraindications, the patient underwent resection of a huge mediastinal tumor before median thoracotomy. The operation was smooth and the intraoperative vital signs were stable. The symptoms of chest tightness and shortness of breath disappeared after operation. The size of the tumor tissue removed after operation was about $45 \times 30 \times 25 \mathrm{~cm}^{3}$ and the weight was about $3.7 \mathrm{~kg}$. The pathological diagnosis was thymolipoma. Postoperative reexamination of chest CT showed that the heart and lungs returned to the normal position. In this case, the operation is effective for large thymic tumors, and the symptoms of the patients are significantly relieved. Early diagnosis and surgical treatment are the key to improve the prognosis of patients. In this study, we reported a successful removal of a giant thymolipoma with complete disappearance of symptoms and no serious complications such as myasthenia gravis, aplastic anemia, and vitamin B12 deficiency.
\end{abstract}

Keywords: Thymectomy; thymolipoma; thymus neoplasms; case report

Submitted Sep 01, 2021. Accepted for publication Nov 17, 2021.

doi: $10.21037 /$ gs-21-651

View this article at: https://dx.doi.org/10.21037/gs-21-651

\section{Introduction}

Lipoma is the most common soft tissue tumor in adults (1). It is characterized by asymptomatic soft tissue masses that can occur throughout the body, with subcutaneous lipomas being more common. Ultrasound, computed tomography (CT), and magnetic resonance imaging (MRI) are important methods for its diagnosis, but the gold standard is still based on histological results $(2,3)$. Lipoma of the thymus is an extremely rare and slow-growing benign tumor, mostly originating from the anterior mediastinum (4). A patient with giant thymolipoma admitted to our department, chest CT showed tumor invasion of bilateral thorax, and the main symptoms were chest tightness and shortness of breath. In this paper, the clinical data of a patient with a giant thymolipoma treated in our department were analyzed, and the pathogenesis, clinical manifestation, and treatment of the disease were reviewed.

We present the following article in accordance with the CARE reporting checklist (available at https://dx.doi. org/10.21037/gs-21-651).

\section{Case presentation}

A 17-year-old male was hospitalized with chest tightness 


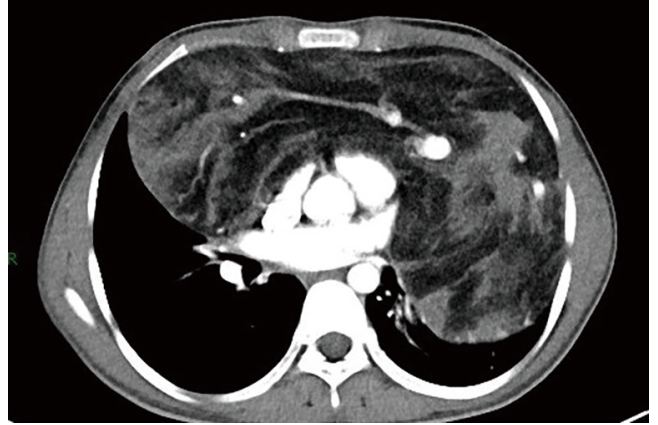

Figure 1 Chest CT examination of the patient on admission.

Table 1 Results of blood biochemical tests of the hospitalized patient

\begin{tabular}{lc}
\hline Blood biochemistry & Results \\
\hline Leukocyte count & $6.1 \times 10^{9}$ \\
Neutrophil granulocyte & $57 \%$ \\
Lymphocyte & $32 \%$ \\
Erythrocyte count & $4.36 \times 10^{9}$ \\
Blood platelet count & $210 \times 10^{9}$ \\
Erythrocyte sedimentation rate & 14 \\
Albumin & $45 \mathrm{~g} / \mathrm{L}$ \\
Prealbumin & $250 \mathrm{mg} / \mathrm{L}$ \\
Blood glucose & $8.87 \mathrm{mmol} / \mathrm{L}$ \\
Alanine aminotransferase & $13 \mathrm{U} / \mathrm{L}$ \\
Aspartate aminotransferase & $22 \mathrm{U} / \mathrm{L}$ \\
Total bilirubin & $13 \mu \mathrm{mol} / \mathrm{L}$ \\
Direct bilirubin & $4.5 \mu \mathrm{mol} / \mathrm{L}$ \\
Indirect bilirubin & $9.4 \mu \mathrm{mol} / \mathrm{L}$ \\
\hline
\end{tabular}

and shortness of breath for 6 months. Six months ago, there was no obvious cause of these symptoms, which were aggravated after activity. A chest CT scan was performed after admission, and it was found that there was a huge mixed density shadow in the anterior mediastinum, multiple patchy fat density shadows (Figure 1), left lower lung compression and atelectasis, partial compression of the right lung, and cardiac pressure to the front of the spine. The patient had no similar family history. After the admission blood biochemical examination (Table 1) and cardiac color ultrasound examination showed that there was no abnormality, the patient underwent median anterior mediastinal resection under general anesthesia. During

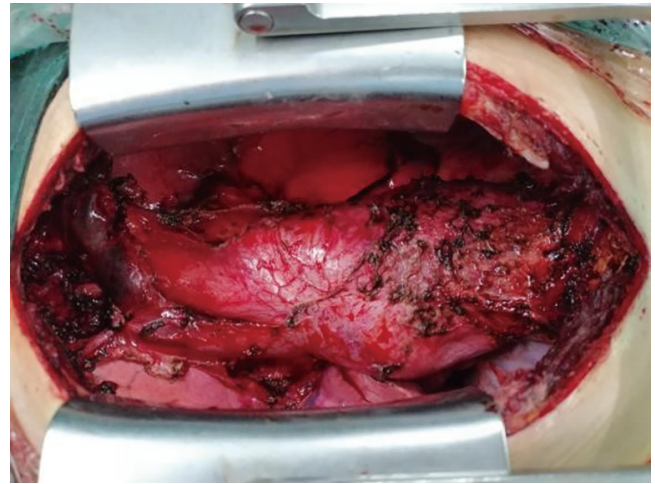

Figure 2 Intraoperative photo of the patient (after tumor resection).

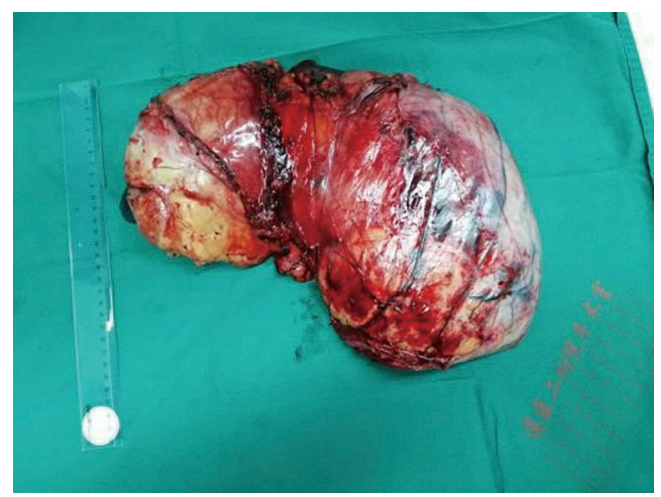

Figure 3 Gross tumor specimen.

the operation, no obvious adhesion was found between the tumor and the lung, pericardium, superior vena cava, and left innominate vein (Figure 2). The tumor was huge and was about $45 \times 30 \times 25 \mathrm{~cm}^{3}$ in size (Figure 3), with a soft and intact capsule. Postoperative pathology showed that the tumor tissue was consistent with thymolipoma (Figure 4), and there was no evidence of malignancy. The symptoms of chest tightness and shortness of breath were improved after the operation. One month later, the chest CT showed redilation of the left lower lung and the heart returned to the normal position (Figure 5).

All procedures performed in studies involving human participants were in accordance with the ethical standards of the institutional and/or national research committee(s) and with the Helsinki Declaration (as revised in 2013). Written informed consent was obtained from the patient's parent for publication of this case report and accompanying images. A copy of the written consent is available for review by the 


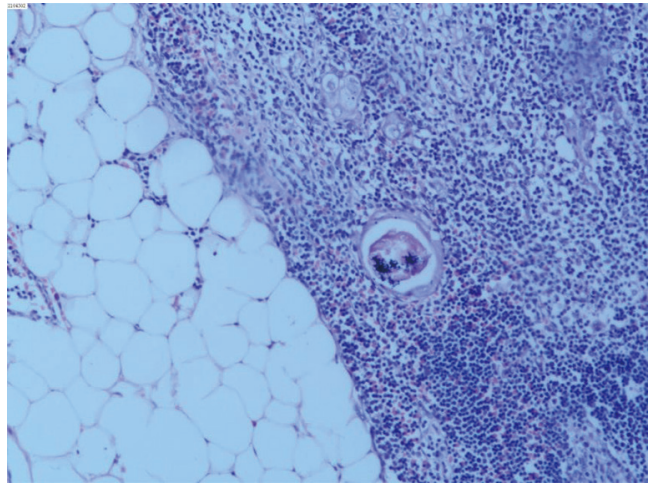

Figure 4 Histopathological results, high power $\times 100$ magnification, haematoxylin and eosin.

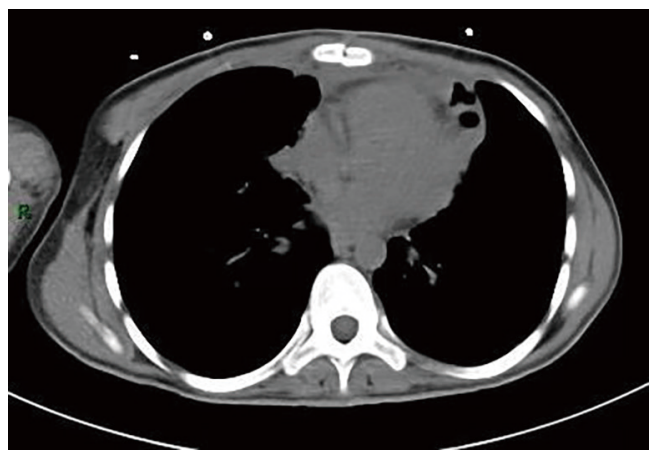

Figure 5 Reexamination of chest CT one month after the operation.

editorial office of this journal.

\section{Discussion}

Thymolipoma is an extremely rare benign tumor of the anterior mediastinum, accounting for $2 \%$ to $9 \%$ of all thymic tumors (5). It was officially named thymolipoma in 1948 (6). The pathogenesis is unknown, and its most widely accepted pathogenesis is that adipose tissue replaces the proliferation of thymic tissue (7). Most thymolipomas are asymptomatic, but when the tumor tissue is significantly enlarged, the compression of nearby tissues and organs causes dyspnea, chest pain, weight loss, and other symptoms $(4,8)$. Some patients with thymolipomas are associated with autoimmune diseases, such as myasthenia gravis, vitamin B12 deficiency, hypogammaglobulinemia, and aplastic anemia. These symptoms will be improved after the lipoma is removed $(9,10)$. Therefore, early diagnosis and surgical intervention are very important to resect the symptoms of compression. Median incision or thoracoscopic resection is the first choice for the treatment of thymolipoma, but for large thymic tumors, median thoracotomy enables extensive contact with the tumor without difficulty. It is recommended that resection should not be reduced or compromised to perform the surgery in a minimally invasive manner $(11,12)$. In this report, chest CT showed that the thymolipoma occupied most of the patient's chest, significantly compressing the cardiopulmonary tube, and compression caused the mediastinum to move to the right. After median thoracotomy to remove the tumor, the symptoms of the patient were significantly improved, and no related myasthenia gravis, vitamin B12 deficiency, or other autoimmune diseases occurred.

\section{Acknowledgments}

Funding: This study was supported by the Science and Technology Project of Guizhou Province [Supported by Guizhou Science and Technology Combined (2021) General 073].

\section{Footnote}

Reporting Checklist: The authors have completed the CARE reporting checklist. Available at https://dx.doi. org/10.21037/gs-21-651

Conflicts of Interest: All authors have completed the ICMJE uniform disclosure form (available at https://dx.doi. org/10.21037/gs-21-651). The authors have no conflicts of interest to declare.

Ethical Statement: The authors are accountable for all aspects of the work in ensuring that questions related to the accuracy or integrity of any part of the work are appropriately investigated and resolved. All procedures performed in studies involving human participants were in accordance with the ethical standards of the institutional and/or national research committee(s) and with the Helsinki Declaration (as revised in 2013). Written informed consent was obtained from the patient's parent for publication of this case report and accompanying images. A copy of the written consent is available for review by the editorial office of this journal.

Open Access Statement: This is an Open Access article 
distributed in accordance with the Creative Commons Attribution-NonCommercial-NoDerivs 4.0 International License (CC BY-NC-ND 4.0), which permits the noncommercial replication and distribution of the article with the strict proviso that no changes or edits are made and the original work is properly cited (including links to both the formal publication through the relevant DOI and the license). See: https://creativecommons.org/licenses/by-nc-nd/4.0/.

\section{References}

1. Johnson CN, Ha AS, Chen E, et al. Lipomatous Softtissue Tumors. J Am Acad Orthop Surg 2018;26:779-88.

2. Al Ghazal P, Grönemeyer LL, Schön MP. Lipomatoses. J Dtsch Dermatol Ges 2018;16:313-27.

3. Furlan K, Miller I, Rohra P, et al. Well-differentiated liposarcoma primary from thymic stroma: Case report and literature review. Exp Mol Pathol 2020;116:104517.

4. Rosado-de-Christenson ML, Pugatch RD, Moran CA, et al. Thymolipoma: analysis of 27 cases. Radiology 1994;193:121-6.

5. Huang CS, Li WY, Lee PC, et al. Analysis of outcomes following surgical treatment of thymolipomatous myasthenia gravis: comparison with thymomatous and non-thymomatous myasthenia gravis. Interact Cardiovasc

Cite this article as: Wang H, Li Q, Jiang Q, Yang Y, Liu Y, Gu $\mathrm{L}$, Gong $\mathrm{M}, \mathrm{Xu} \mathrm{G}$, Chen C. A giant tumor of the mediastinum mixed with thymocytes and adipocytes: a case report. Gland Surg 2021;10(11):3163-3166. doi: 10.21037/gs-21-651
Thorac Surg 2014;18:475-81.

6. Hall GF. A case of thymolipoma with observations on a possible relationship to intrathoracic lipomata. Br J Surg 1949;36:321-4.

7. Argani P, de Chiocca IC, Rosai J. Thymoma arising with a thymolipoma. Histopathology 1998;32:573-4.

8. Ganesh Y, Yadala V, Nalini Y, et al. Huge mediastinal mass with minimal symptoms: thymolipoma. BMJ Case Rep 2011;2011:bcr0520102984.

9. Othman SA, AlFrayyan OY, AlGhamdi ZM, et al. Thymolipoma Association with Myasthenia Gravis: Case Report. Am J Case Rep 2020;21:e923989.

10. Wang Y, Sun Y, Zhang J, et al. Diagnosis, treatment and prognosis of thymoma: an analysis of 116 cases. Chin Med J (Engl) 2003;116:1187-90.

11. Detterbeck FC, Moran C, Huang J, et al. Which way is up? Policies and procedures for surgeons and pathologists regarding resection specimens of thymic malignancy. J Thorac Oncol 2011;6:S1730-8.

12. Toker A, Sonett J, Zielinski M, et al. Standard terms, definitions, and policies for minimally invasive resection of thymoma. J Thorac Oncol 2011;6:S1739-42.

(English Language Editor: C. Betlazar-Maseh) 